\title{
A collaborative knowledge management framework for supply chains. A UML-based model approach
}

\author{
Jorge Esteban Hernández; Raúl Poler; Josefa Mula; David Peidro
}

Centro de Investigación Gestión e Ingeniería de Producción (CIGIP)

Universidad Politécnica de Valencia (SPAIN)

jeh@,cigip.upv.es; rpoler@,cigip.upv.es; fmula@,cigip.upv.es; dapeipa@,cigip.upv.es

Received October 2008

Accepted November 2008

\begin{abstract}
Nowadays, information technologies imply a strong modelling approach to support the complexities involved in the supply chain management process. Since supply chains are made up of nodes, which need to reach common agreements in order to fulfil their own requirements, the information technologies-based model is an adequate tool to support the modelling of the knowledge management process, mainly in a collaborative context. In the most general cases, collaborative activities also imply a distributed decisionmaking process which involves several supply chain nodes. Because collaboration in supply chains implies information exchanges among the nodes, the framework proposal is oriented to support knowledge management by considering the information sharing process as one of the main aspects. Therefore by means of a literature review and by also considering the deficiencies of existing proposals, a collaborative knowledge management UML-based framework is herein proposed which encompasses both the conceptual and general perspectives of the supply chain management process. Finally, the proposed framework summarises existing knowledge by not only fulfilling but also enriching each of its components with the modeller's own knowledge.
\end{abstract}

Keywords: knowledge management, unified modelling language, framework, collaborative supply chain. 


\section{Introduction}

The supply chain (SC) management process identifies goals, objectives and outlining policies, strategies and controls for its effective and efficient implementation (Smirnov \& Chandra, 2000). In addition, Dubey, Veeramani and Gutierrez (2002) establish that the SC considers a set of approaches utilised to efficiently integrate companies, which compose the workgroups, in order to correctly produce and distribute customer requirements. In this context, it is possible to support knowledge management (KM) in a collaborative manner by sharing the right information among the players of these workgroups. Then in order to train people, by not only forming different workgroups, but also simultaneously working on different tasks, two types of sessions are used in the collaborative engine (which can also be understood as the collaborative process), these being user sessions to identify online users and collaboration sessions to represent a group of customers involved in the same collaboration ( $\mathrm{Ni}, \mathrm{Lu}$, Yarlagadda, \& Ming, 2006) which enhances KM. Then in order to fulfil the supply chain management requirements to support collaboration among its members (companies or nodes), this paper will consider the information flow (information sharing or transfer) among them in order to support and study the KM process in the SC. We refer readers to Aurum, Daneshgara, Warda (2008) in order to carry out an in-depth study on the knowledge management basis.

Recently, many studies have been done in the collaborative supply chain field and on its modelling implication. In this context, some suggested literature in this field are: Bafoutsou and Mentzas (2002); Saad, Jones, \& James (2002); Gunasekaran and Ngai (2005); Meixell and Gargeya (2005); Fawcett, Osterhaus, Magnan, Brau and McCarter (2007); Fawcett, Magnan and McCarter (2008) and van der Vaart and van Donka (2008). In light of this, a literature review considering the most relevant papers on this matter has been done with a view to finding the main aspects and tools considered to support the $\mathrm{KM}$ in the SC under a collaborative approach. Thus, our review shows that the main aspects are related to the following subjects: new development software tools (ST) to support the KM process; decision-making processes; document management and SC management. Regarding the ST, Núñez and Núñez (2005) propose a classification to detect and understand their common applications. As a result, the most considered aspects found were those related to the decision-making process, which mainly uses 
information analysis tools. Conversely, the least considered aspect is that regarding the $\mathrm{SC}$ as a whole. This is related to the fact that $\mathrm{KM}$, in a SC context, tends to be modelled as a centralised concept in relation to each workgroup element. Therefore, this paper proposes a framework which considers and supports collaboration among the SC nodes that is supported by considering a modelling tool approach.

The rest of the paper has been arranged as follows. Section 2 shows an overview related to the main topics to be considered in the framework. Section 3 presents an analysis of Section 2 in order to collect the main aspects and concepts that will support the framework achievement. Section 4 proposes a collaborative knowledge management UML-based framework to support collaboration in the supply chain management process. Finally, Section 5 provides the conclusions and further research.

\section{Background}

\subsection{Collaboration in the supply chain management process}

Supply chain management involves all the activities in industrial organisations from raw material procurement to final product delivery to customers (Soylu, Oruc, Turkay, Fujita, \& Asakura, 2006). In addition, the decisions related to these activities may be identified as strategic, tactical and operational levels where each decisional level will affect the long-, mid- and short-term, respectively. In this context, supply chain management (SCM) is defined by the Global Supply Chain Forum (GSCF) as the integration of key business processes from end users through original suppliers that provide products, services and information which add value to customers and other stakeholders (Lambert \& Cooper, 2000). As a result, SCM embraces various business processes and firms/companies which are of relevance to service customers: order fulfilment, customer service management and product development (Cooper, Eilram, Gardner, \& Hanks, 1997). In this context, by promoting the integration of the firms belonging to the SC, Sigala (2008) establishes that an increase in the overall SC performance, total business-process excellence and end-consumer satisfaction, rather than self-competition, becomes one of the most relevant aspects for a bigger profit share. Moreover from the conceptual studies conducted by Turkay, Oruc, Fujita and Asakura (2004), it is possible to highlight the importance of SCM by fostering the strategic companies 
relationships in increasing the companies' financial and operational performance, which ultimately results in better information exchange among companies. Furthermore in relation to the dynamical environment in which companies are immersed, sharing information among customers supports the creation of collaborative supply chains that are capable of competing in a particular leading industry (Ketikidis, Koh, Dimitriadis, Gunasekaran, \& Kehajova, 2008). This is precisely why the SCM process may be considered a systematic and strategic coordination of traditional business functions and tactics not only across these business functions within a particular company, but also and across businesses within the supply chain (Lejeune \& Yakova, 2005). Then Williamson, Harrison and J ordan (2004) state that by synchronising the operation of all the companies in the SC, the effectiveness of the SCM process can be achieved. An example of this is provided by Eng (2004), who establishes that by considering business-to-business electronic marketplaces, the use of Internet protocol communications has gained a widespread implication in SCM by facilitating the information sharing process among the supply chain nodes or companies.

Then collaboration in supply chain management considers that the outcomes of the collaboration among supply chain companies, which also share losses and gains, must be quantifiably beneficial for everyone (Manthou, Vlachopoulou, \& Folinas, 2004). These authors also state that each member must be able to share information with trading partners and customers in real time, which can be supported by virtual networks or e-supply chains to, in turn, support the collaboration among them. Thus, it can be said that e-collaboration facilitates the coordination derived from various decisions and activities beyond transactions among SC partners, both suppliers and customers, over the Internet (Rosenzweig $\&$ Roth, 2007). Furthermore, SC collaboration (in practice) usually starts with an uncomplicated scenario due to the low mutual trust between trading partners. Then this mutual trust may gradually increase and lead to a boost in confidence in a complicated and profound collaboration mechanism (Chen, Yang, \& Li, 2007). It is also important to consider that collaboration in a SC may be present in many varying forms, but it generally has a common goal: to create a transparent and visible demand pattern that paces the entire supply chain (Holweg, Disney, Holmstrom, \& Smaros, 2005). Another fact established by Holweg et al. (2005) is to achieve more transparent information in order to reduce uncertainty in the environment, which is another of the goals of the collaborative processes in the SC. 
Moreover, Kwon, Im and Lee (2007) establish that one purpose of modelling relationship uncertainty is to reflect on the different degrees of information sharing across relationships. Information sharing is known as the most effective method to encounter demand information distortion problems. In this context, and in relation to the level of information sharing, Holweg et al. (2005) define four types of supply chains: Type 0 (traditional supply chains in which just one type of information is available among the companies/nodes), Type 1 (supply chains based on information exchange in which information helps the node to improve its decision process), Type 2 (supply chains based on vendor-managed replenishment in which the decision-making process responsibility is distributed), and finally, Type 3 (synchronised supply chains in which sharing information enables the nodes to eliminate decisions and to merge others to fulfil their requirements). It is also important to consider the fact that even if the collaboration in the SC has a potential benefit under a collaborative environment, non-collaborative decentralised behaviours prevail in most real cases (Son \& Sheu, 2008). Moreover in most cases, traditional communication media cannot provide real-time information exchange and sharing. Therefore, potential problems, such as out-ofdate design concepts or production plans, may occur owing to information inconsistency and communication delays (Trappey \& Hsiao, 2008). This is one of the biggest drawbacks to be considered when collaborative approaches are about to be contemplated in the SC modelling process.

\subsection{Knowledge collaboration in the supply chain}

Two main aspects are commonly considered in the study of the collaboration relationship in the SC: the first deals with the intensity of the relationships between partners whose considerations vary from simple information sharing to risk and profits information sharing; the second studies the extent of the collaboration across the SC (La Forme, Genoulaz, \& Campagne, 2007). In this context, Nonaka (1991) establishes that knowledge can be understood as the information flow among the resources within the company. Information flow can come about from the worker's experience or be a result of the physical document generation process (which, in our case, can also be understood as knowledge), where tacit knowledge may be most important because it is one of that is most unpredictably and uneasily expressed. In relation to this, Hall and Adriani (1998) established a validation technique to analyse the role of the intangible resources in individual firms. 
Therefore, this technique establishes a code from tacit knowledge and allows a good understanding of this kind of information, which establishes a basis to join strategic developments. In relation to this fact, the management process can be collaboratively developed among managers by exchanging perceptions and by also discussing alternative futures. In this context, Boddy, Macbeth and Wagner (2000) highlight the fact that many managers address the development of collaborative alliances with other organisations. But very often, these strategies cannot be easily implemented, and they are just as likely to fail as to succeed. Therefore, the authors studied this collaborative concept with an empirical study of one alliance type in the SC. As a result, a cooperative behaviour may emerge from human action which considers interaction partnering as a main activity. Moreover from a buyer-supplier relationship context, Hoyt and Huq (2000) establish that this kind of relationship plays an important role in permitting a good response to the dynamic and unpredictable change in the environment. Moreover, Dyer and Singh (1998) highlight the fact that this sharing of knowledge and resources under a collaborative context could generate relational incomes to SC partners. Therefore, as knowledge exchange may also be understood as an information exchange among partners, Simatupang and Sridharan (2002) establish that asymmetric information is always a problem among SC members, mainly because, more often than not, these partners do not like to share their private information completely. Therefore when knowledge/information must be shared, it must be managed in such a way that it develops over a period of time (Sahay, 2003). So, it is necessary that managers should not only be skilled in technical and operational areas, but should also develop relationships that favour the trust required to encourage information exchange. Moreover, knowledge collaborations can be perceived from different degrees of collaboration. In this context, and by considering the nine steps suggested by VICS (voluntary interindustry commerce solutions), SkjoettLarsen, Thernøe and Andresen (2003) define collaborative relationships as collaboration where two or more parties in the SC jointly plan a number of promotional activities and work out synchronised forecasts on the basis of which production and replenishment processes are determined. Then, Barratt (2000) establishes that there are many elements of collaboration in SC management, such as trust, mutualness, information exchange, openness and communication. Therefore, it is possible to see that these collaborative elements are intrinsically oriented to support a collaborative knowledge management process. For instance, Ulieru, Norrie, Kremer and Shen (2000) propose a recursive multi-resolution 
collaborative architecture based on a multi-agent coordination mechanism. Then, the knowledge management process is assigned to agents who are able to retrieve information for specific applications from databases, made possible by considering mechanisms that use intelligent queries. Furthermore, these agents are also able to process the information by storing, transforming and transporting it.

Another perspective is that by proposed Blanc, Ducq and Vallespir (2007) who establish that the cooperation among organisations is provided by the SC. Therefore enterprises must interoperate. In this context, these authors establish that interoperability can be achieved by eliminating the heterogeneity present in the environment. Thereafter, Blanc et al. (2007) consider that the heterogeneity problem must be studied from two points of view: semantic and organisational. Additionally, the authors present an application of the ECOGRAI method, and they implement it by considering information technology (IT) in an interoperability application framework. In addition, Han, Chin and Chae (2007) consider the fact that the use of IT has effectively promoted the integration of fragmented information, and that under a collaborative environment (specifically an Internetbased system), there are not enough standard formats to transmit contractual documents and project-related information by simply considering the issue of data compatibility. To solve this, Han et al. (2007) consider the knowledge management function by implementing distributed databases containing the transactions of documents done during a project life cycle. This helps cut the total time invested and the costs required. Linking enterprise models, mainly those related to the enterprise environment in which the enterprise goals and strategies are considered to be the first step in the software development process, and which involve establishing a requirements elicitation, are presently becoming a very common research trend (Grangel, Chalmeta, \& Campos, 2007a; Grangel, Chalmeta, \& Campos, 2007b; Grangel, Chalmeta, Campos, Sommar, \& Bourey, 2008). From another point of view, Lin and Harding (2007) study languages, or information models, to obtain the ontology needed to favour knowledge representation. Therefore, a manufacturing system engineering ontology model is presented. This model has been created to enable an adequate sharing of communication and information with a language that is a web-service standard and which supports the ontology model. Another example is that by Tann and Shaw (2007) who propose a knowledge-based design support system under a collaborative modelling framework. Finally Gunasekaran, Lai and Cheng (2008) establish several areas (or 
elements) with a collaborative knowledge management process and IT in the SC that must be taken into account: strategy formulation, tactical management, operations control, and systems. The authors determine that the selection of technologies depend on the strategies which meet most of the company's requirements.

\section{Main supply chain modelling aspects identified}

From the previous sections, many concepts and aspects to understand both the supply chain management process and knowledge management from a collaborative perspective have been identified. In this context, this section highlights these aspects in order to detect those which may have a greater impact on the development of the proposed framework. Therefore, the following subsection covers the background study based on the collaboration process in the SC on the one hand, and the knowledge management background to detect how knowledge can be interpreted as information flow on the other hand.

\subsection{The collaborative approach}

With a collaborative approach, many concepts and conceptual elements in the field of supply chain management can be recovered. Thus, in order to target efforts in such a broad study of this nest of knowledge, only five dimensions of study have been included: (1) Interpretation of collaboration (as collaboration can be seen from different point of views, our interest is to detect a certain pattern that may be useful for the framework proposal), (2) supply chain configuration (this dimension considers the configuration defined by Beamon and Chen (2001) to detect how the authors cover the supply chain study from its physical point of view), (3) the framework approach considered (this dimension addresses whether or not a framework is presented), (4) modelling technique and (5) technology (dimensions (4) and (5) address the modelling technique and technology considered to support their research work).

Table 1 shows that half the authors (50\%) conceive the collaboration in the SC as a sharing information process in either a dyadic (two nodes) or net (many nodes) supply chain configuration, where net configuration is selected the most $(81 \%)$ to develop and present their models. Similarly we can see that the idea of presenting a conceptual approach-based framework is common among the authors (50\%). On 
the one hand, this enables the development of models in terms of simpler elements but which, on the other hand, take fully into account concepts and their relationships at all the levels. Finally, Table 1 highlights the fact that less than half $(44 \%)$ of the authors consider a framework for their research work.

\begin{tabular}{|c|c|c|c|c|c|}
\hline Authors & $\begin{array}{l}\text { Interpretation of } \\
\text { collaboration }\end{array}$ & $\begin{array}{l}\text { Supply chain } \\
\text { configuration }\end{array}$ & $\begin{array}{l}\text { Framework } \\
\text { approach } \\
\text { considered }\end{array}$ & $\begin{array}{l}\text { Modelling } \\
\text { technique }\end{array}$ & Technology \\
\hline Cooper et al. (1997) & $\begin{array}{l}\text { Integrated companies } \\
\text { relationships }\end{array}$ & Dyadic & NE & Conceptual & NE \\
\hline Chen et al. (2007) & $\begin{array}{c}\text { CPFR } \\
\text { Information sharing }\end{array}$ & Net & NE & Simulación & Rockwell Arena ${ }^{\circledR}$ \\
\hline Eng (2004) & Information sharing & Net & Yes & Sematic representation & NE \\
\hline Holweg et al. (2005) & Collaborative planning & Dyadic & Yes & Conceptual & NE \\
\hline Ketikidis et al. (2008) & $\begin{array}{l}\text { Information sharing } \\
\text { (demand planning) }\end{array}$ & Net & NE & NE & $\begin{array}{c}\mathrm{SPSS} \circledast \\
\text { (data analysis) }\end{array}$ \\
\hline Kwon et al. (2007) & $\begin{array}{l}\text { Information sharing and } \\
\text { coordination }\end{array}$ & Net & Yes & $\begin{array}{c}\text { Date base } \\
\text { Mathematical } \\
\text { Graph } \\
\end{array}$ & $\begin{array}{l}\text { JDK1.4.1 and Apache } \\
\text { SOAP 2.0, MsAccess }{ }^{\circledR}\end{array}$ \\
\hline Lambert and Cooper (2000) & $\begin{array}{l}\text { Management of multiple } \\
\text { relationships in the supply } \\
\text { chain }\end{array}$ & Net & Yes & Conceptual & NE \\
\hline Lejeune and Yakova (2005) & $\begin{array}{l}\text { Internal cross-functional } \\
\text { integration }\end{array}$ & Net & NE & NE & NE \\
\hline Manthou et al. (2004) & $\begin{array}{c}\text { Flow of information, } \\
\text { services and } \\
\text { products along the supply } \\
\text { chain }\end{array}$ & Net & Yes & Web-Based & $\begin{array}{l}\text { HTTP } \\
\text { XML } \\
\text { CORBA }\end{array}$ \\
\hline Rosenzweig and Roth (2007) & Information sharing & Net & Yes & Conceptual & eBusiness \\
\hline Sigala (2008) & Information sharing & Net & Yes & Conceptual & NE \\
\hline Son and Sheu (2008) & $\begin{array}{c}\text { Activities oritented to supprt } \\
\text { joint planning, demand } \\
\text { forecasting, merchandise } \\
\text { optimization, and order } \\
\text { fulfillment }\end{array}$ & Net & NE & Simulation & $\begin{array}{c}\text { Crystal Ball Professionals } \\
\circledR \text { and OptQuest }\end{array}$ \\
\hline Soylu et al. (2006) & Information sharing & Net & NE & $\begin{array}{l}\text { Conceptual } \\
\text { Mathematical }\end{array}$ & $\begin{array}{l}\text { GAMS } \\
\text { CPLEX }\end{array}$ \\
\hline Trappey and Hsiao (2008) & $\begin{array}{l}\text { Real-time design changes } \\
\text { Consistency of information }\end{array}$ & Net & NE & $\begin{array}{l}\text { Conceptual } \\
\text { UML }\end{array}$ & NE \\
\hline Turkay et al. (2004) & Information sharing & Net & NE & $\begin{array}{l}\text { Conceptual } \\
\text { Mathematical }\end{array}$ & ILOG CPLEX \\
\hline Williamsom et al. (2004) & $\begin{array}{c}\text { Joint inventory } \\
\text { management } \\
\text { Information sharing }\end{array}$ & Dyadic & NE & NE & EDI \\
\hline
\end{tabular}

Table 1. "Relevant collaborative aspect within supply chain management"..

\subsection{Knowledge management modelling approach}

This section presents the knowledge management process in terms of the literature review. Firstly, this analysis considers the following identified aspects (Table 2): (P1) development of new products, (P2) modelling, (P3) decision-based support, (P4) documental management, (P5) SC management and (P6) framework. Secondly, the classification by Núñez and Núñez (2005) is considered. This classification observes how the IT and software tools are involved. Thereafter, this classification considers (Table 3 ) the following seven aspects: $(\mathrm{H} 1)$ tools oriented 
to search and recover information, ( $\mathrm{H} 2$ ) customising and filtering information tools, (H3) storage and information management, (H4) information analysis tools, (H5) flow and communication management systems, (H6) learning tools and (H7) enterprise management systems.

\begin{tabular}{|l|l|l|l|l|l|l|l|}
\hline \multicolumn{1}{|c|}{ Authors } & H1 & H2 & H3 & H4 & H5 & H6 & H7 \\
\hline Barrat (2000) & & & & & & & \\
\hline Blanc et al (2007), & & & & & & & \\
\hline Body et al (2000) & & & & & & & \\
\hline Dyer and Singh (1998) & & & & & & & \\
\hline Grangel et al (2007a) & & & & & & & \\
\hline Grangel et al (2007b) & & & & & & & \\
\hline Grangel et al (2008) & & & & & & & \\
\hline Gunasekaran et al (2008) & & & & & & & \\
\hline Hall and Adriani (1998) & & & & & & & \\
\hline Han et al (2007) & & & & & & & \\
\hline Hoyt and Huq (2000) & & & & & & & \\
\hline Lin and Harding (2007) & & & & & & & \\
\hline Nonaka (1991) & & & & & & & \\
\hline Sahay (2003) & & & & & & & \\
\hline Simatupang and Sridharan (2002) & & & & & & & \\
\hline Skjoett-Larsen et al. (2003) & & & & & & & \\
\hline Tan and Shaw (2007) & & & & & & & \\
\hline Ulieru et al (2000) & & & & & & & \\
\hline
\end{tabular}

Table 2. "Main aspects identified".

\begin{tabular}{|l|l|l|l|l|l|l|}
\hline \multicolumn{1}{|c|}{ Authors } & P1 & P2 & P3 & P4 & P5 & P6 \\
\hline Barrat (2000) & & & & & & \\
\hline Blanc et al (2007), & & & & & & \\
\hline Body et al (2000) & & & & & & \\
\hline Dyer and Singh (1998) & & & & & & \\
\hline Grangel et al (2007a) & & & & & & \\
\hline Grangel et al (2007b) & & & & & & \\
\hline Grangel et al (2008) & & & & & & \\
\hline Gunasekaran et al (2008) & & & & & & \\
\hline Hall and Adriani (1998) & & & & & & \\
\hline Han et al (2007) & & & & & & \\
\hline Hoyt and Huq (2000) & & & & & & \\
\hline Lin and Harding (2007) & & & & & & \\
\hline Nonaka (1991) & & & & & & \\
\hline Sahay (2003) & & & & & & \\
\hline Simatupang and Sridharan (2002) & & & & & & \\
\hline Skjoett-Larsen et al. (2003) & & & & & & \\
\hline Tan and Shaw (2007) & & & & & & \\
\hline Ulieru et al (2000) & & & & & & \\
\hline
\end{tabular}

Table 3. "Tool classification".

Table 2 shows that the most repeated aspect is modelling (P2), which is considered by $89 \%$ of the works reviewed. It is followed by decisional support (P3) and supply chain management (72\%) (P5). This in relation to the fact that $\mathrm{KM}$, which is mainly an intangible concept in a supply chain context, must be modelled in order to visualise it and to detect the critical process points which are related to the decision-making process since knowledge is information used to support this process. The last dimension of Table 2 refers to the framework approach. Therefore, Table 2 shows how half the authors relate the knowledge management process in the SC by considering a collaborative process that is present in a framework within their research work. Table 1 highlights that developing a framework, which considers information flow in the net supply chain configuration, is important. Moreover from the tool classification (Table 3), the information analysis tool $(\mathrm{H} 4)$ is the most widely used concept $(72 \%)$, followed by information filtering ( $\mathrm{H} 2$ ) with $61 \%$, and the management flow system (H5) with $67 \%$. However, the least considered aspect is the development of new products (P1) with $39 \%$. From a tool classification point of view, the least considered aspects are learning tools $(\mathrm{H} 6)$ and storage tools $(\mathrm{H} 1)$, both with $33 \%$. In the light of these 
results, an upgrading process of existing products that has been in use for many years not only has to be taken into account, but also that knowledge presents more difficulties to apply these kinds of technologies or tools to manage the knowledge process.

Another contribution to the analysis is shown in Table 4 which relates both dimensions (aspects and tools) and shows how the authors simultaneously consider both. Green circles represent the combination with the most considerations; red circles represent the combination with the least considerations, while blue squares represent those options with average considerations.

\begin{tabular}{|c|c|c|c|c|c|c|}
\cline { 2 - 8 } \multicolumn{1}{c|}{} & P1 & P2 & P3 & P4 & P5 & P6 \\
\hline H1 & 5 & 6 & 5 & 3 & 6 & 3 \\
\hline H2 & 6 & 11 & 10 & 8 & 7 & 8 \\
\hline H3 & 4 & 7 & 6 & 6 & 4 & 5 \\
\hline H4 & 4 & 11 & 8 & 8 & 7 & 9 \\
\hline H5 & 4 & 10 & 7 & 8 & 7 & 7 \\
\hline H6 & 4 & 5 & 4 & 4 & 5 & 4 \\
\hline H7 & 3 & 8 & 7 & 6 & 5 & 7 \\
\hline
\end{tabular}

Table 4. "Crossed table of tools and detected aspects".

Table 4 highlights the good relationship that exists between modelling with both customising and filtering information tools and information analysis tools. Therefore, the information treatment results, which are an important aspect to be considered in the modelling process, are accomplished. In addition, another important relationship that may be detected is found between the framework and information analysis tools. This relationship occupies the middle area of the authors' preferences. Another important aspect to consider is that, besides contemplating information as a critical aspect in developing a framework, a tool that may support this model must be defined. Therefore, the following section presents the conceptual collaborative framework that supports the SCM process (under the knowledge management approach). 


\section{Collaborative knowledge management UML-based framework to support the supply chain management process}

\subsection{A conceptual knowledge management model to support collaboration in the supply chain}

A conceptual model can be defined as the descriptive tools that underline the main aspects and relevant variables involved in a specific problem and/or empirical structures to propose guidelines to deal with the problems of a modelling domain (Giannoccaro \& Pontrandolfo, 2001). Moreover, a conceptual representation allows modellers to understand the system behaviour, and it also provides an overall view (Hernández, Mula, Ferriols, \& Poler, 2008). In this context, the knowledge management framework (KMF) proposal, whose objective it is to represent and understand SC-related interdependences, emerges as an extension of the work of Nonaka (1991) by considering the work of Hernández et al. (2008) as a modelling methodology. As previously mentioned, Nonaka (1991) indicates that tacit and explicit knowledge flow generates four types of knowledge processes: socialisation, externalisation, combination and internalisation. Additionally, the optimal development of this process will depend on the behaviour of each enterprise. In an optimal development process, the enterprise's continuous learning process should be obtained. Furthermore, the socialisation process is supported by people, which means that it is a process in which people transfer their tacit knowledge. Next, the externalisation process turns tacit knowledge into explicit knowledge. This occurs when an idea is written on paper, meaning that externalisation turns individual matters into group matters. The combination process, however, uses IT to transmit or share knowledge, and introduces a greater usability of knowledge. Thereafter explicit knowledge becomes new explicit knowledge. Finally, the internalisation process takes place and processes any explicit knowledge generated to transmit it to the corresponding workgroups, which will once again generate new tacit knowledge from it.

Therefore, the proposed KMF (see Figure 1) considers six elements:

- I nputs/ outputs: Represents the inputs and outputs that IT architectures establish to support the knowledge management process. These can take two representative forms: explicit (documents, BBDD tables, etc.) or tacit (conversations, experiences, etc.). 
- Environment/ culture: Define the space of interaction among entities (supply chain nodes). This area is governed by the existing predominant organisational climate and culture, factors which are relevant for the proper flow and knowledge generation (informational flow).

- Knowledge management process (function): This is the most important process and is responsible for delivering dynamism to the environment in accordance with the needs that arise from it and with the decisions needed to be taken. This function is also responsible for validating intangibles, or knowledge, through the achievement of documents, whether physical or electronic, which may prevail in time. In addition, this document may be used, for example, to analyse and establish improvements. Then, this process interacts with the two types of knowledge defined by Nonaka (1991) that are detectable in the organisation (tacit and explicit). Thus, the knowledge management process can receive knowledge (information) through processes such as produce, and internalise it in the company.

- Knowledge types: This relates to inputs/outputs, via the knowledge management process, and knowledge can be seen in four perspectives. Explicit knowledge \#, which is explicit knowledge generated from an existing explicit knowledge, which then defines tacit knowledge \#, which will be read as that knowledge from explicit knowledge \#, and will provide relevant facilities to generate new tacit knowledge. Therefore, the framework's life cycle goes through these four knowledge types or forms.

- Input/ output connectors: They represent what the knowledge management process intends to provide to the environment (creation), and what should be known (receiving) to allow better action control.

- Technological information tools: this block represents the models, or architectures, at the information technology level which support the decision-making process in the environment. These architectures support the mobility of the system through the collection of knowledge, which can be expressed (as already mentioned) in physical documents or ideas. In addition, they support the generation of new knowledge. This last concept is established by the criteria imposed by the environment in the knowledge process. 
Moreover, the proposed model combines the best works from the studied literature presented in the background, but incorporates new elements. This model, or framework, with its seven elements, also links the KM process with the knowledge detected in companies or workgroups. As Figure 1 depicts, the model considers the definition of the environment which consists in a series of knowledge processes and entities that interact with each another, but always under a labour environment and culture. These last two elements provide information related to the beliefs, desires and interactions of the entities which make up the environment. Then in relation to an adequate knowledge management process (which depends on the objectives and interests of the entities that make up the environment), it is possible to capture the correct necessities which support the decision-making process. Therefore, this management process consists in handling different types of knowledge that, through information technologies, generate the four main and already known processes to be considered (socialisation, externalisation, combination and internationalisation). In addition to supporting the development process of the model, two knowledge types are added to this model: tacit and explicit. These relate to the new knowledge generated from the knowledge management process which allows a better understanding of the environment, and which also supports continuous improvement in the workgroups.

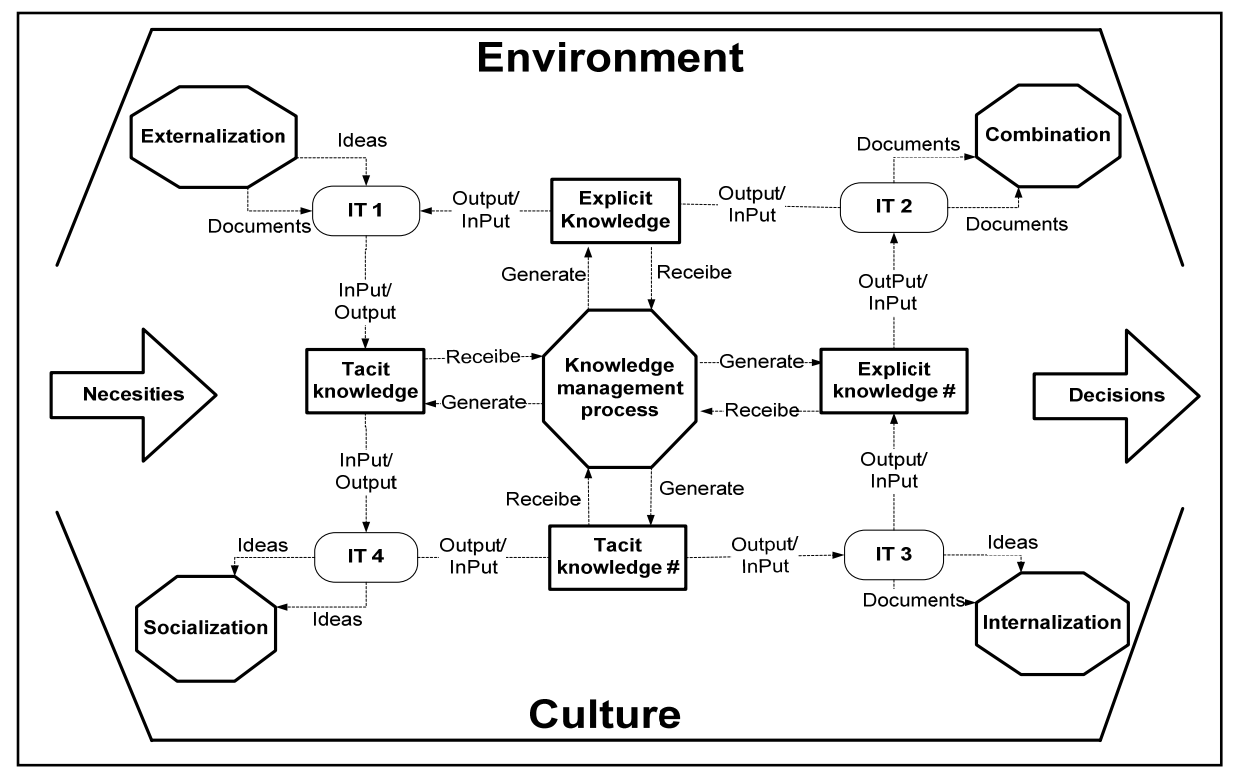

Figure 1. "KMF proposal, a conceptual perspective -An extension of Nonaka (1991)-".

Then, another contribution emerges from the proposed model which is related with IT architectures. Therefore to obtain four types of knowledge (tacit, explicit, tacit\# 
and explicit\#), it is necessary to consider the right definition and configuration of the IT systems. Thus, four IT types are contemplated, which are in charge of receiving, processing and generating new information that, at the same time, could be used as an information input for the other IT present in the environment. Should some IT systems of the SC nodes be the same, it could be possible to use a centralised system. Regardless of whether it is the same IT system or different ones, each SC node could have its own IT data process. Additionally, a dialogue could be established with a series of protocols where data and information would add value to both the environment and the SC, which could also be defined.

\subsection{A collaborative knowledge management framework supported by the UML-based model}

According to Huang, Chu, Li and Yen (2008), the selected language to support this architecture is UML (Booch, Rumbaugh, \& Jacobson, 1997). In this context, UML presents a high level of simplicity, a good level of formalism, and provides a well standardised modelling tool. This formalism allows concepts and ideas to be easily transmitted to different kinds of people belonging to the workgroup in a SC. Moreover, collaboration in a SC needs to solve conflicts among several decentralised functional units because each unit attempts to locally optimise its own objectives rather than the overall SC objectives. The KMF (Figure 2) is extended to support the information flow among the SC nodes as a KM process. Yesilbas and Lombart (2004) also detect three types of collaborative knowledge (pre, in and post) to support the process design. From a centralised view therefore (Figure 1), and in relation to Grangel et al. (2007a); Grangel et al. (2007b) and Grangel et al. (2008), UML concepts are used to support the connection among the SC nodes. Then in the presence of a complete, partial or non-collaborative process in the SC, it allows alternative views of the informational flow to be generated in relation to the corresponding $\mathrm{KM}$ process, and each is based on this collaborative KMF proposal.

The UML notation is used to support the corresponding IT connection. Therefore, the proposed collaborative knowledge management framework (CKMF) uses this notation to establish and formalise the connection among the nodes forming the SC. Moreover, it is assumed that each node has agreed to share information. So each IT displayed in Figure 1 is related to one type. In this context, the selected UML diagrams are deployment, class and sequence because their diagrams are the 
most representative to clearly manage and express the two types of knowledge defined by Nonaka (1991): tacit and explicit. In addition, and from a generic point of view (Figure 2), a dyadic supply chain (two nodes) is considered to obtain a simple representation. Later, Subsection 4.3 shows a more specific and real supply chain configuration that extends this dyadic approach.

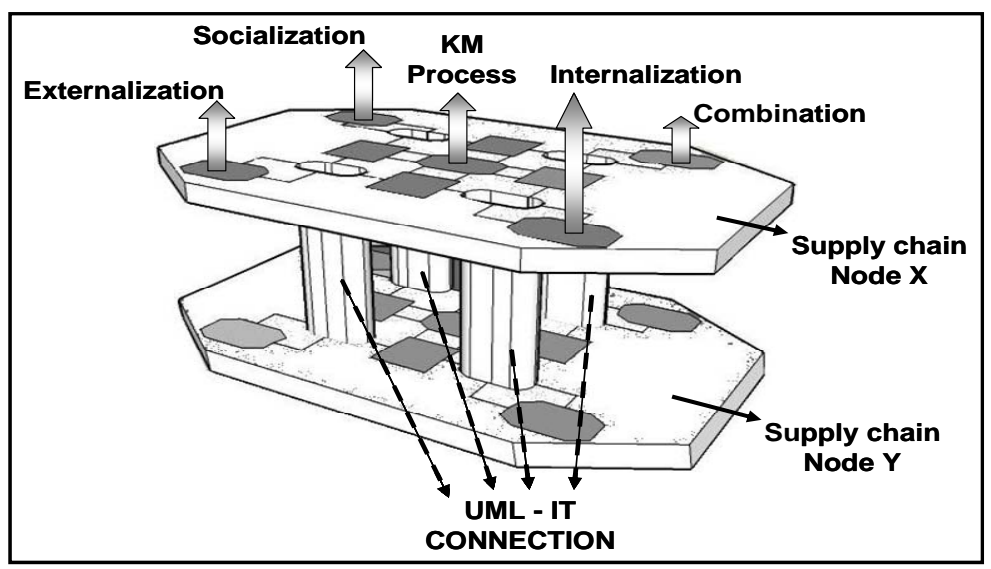

Figure 2. "Extended KMF to support the collaborative process in the SC by UML (a dyadic approach)".

- Knowledge management process: from a centralised perspective, this process is represented by a UML component diagram to be able to identify the main aspects of this process. Then receiving and generating information are considered as main attributes of this process.

- IT 1, the deployment diagram: here the $X$ and $Y$ nodes are represented by an artefact where the information flow enters and exits the knowledge system node in order to represent tacit and explicit knowledge, respectively. In addition, a knowledge system is connected to another node which represents a database (BBDD) system by considering a one-to-one relationship in the light of the fact that there must be a correct correspondence with shared information (tacit and explicit).

IT 2, the class diagram: given the intention of grouping the different categories present in the knowledge management process, the UML class diagram is properly considered to be used for processing explicit knowledge in order to obtain new explicit knowledge. Then two nodes are defined to cover, or support, the intrinsic knowledge process in the SC. Moreover, each 


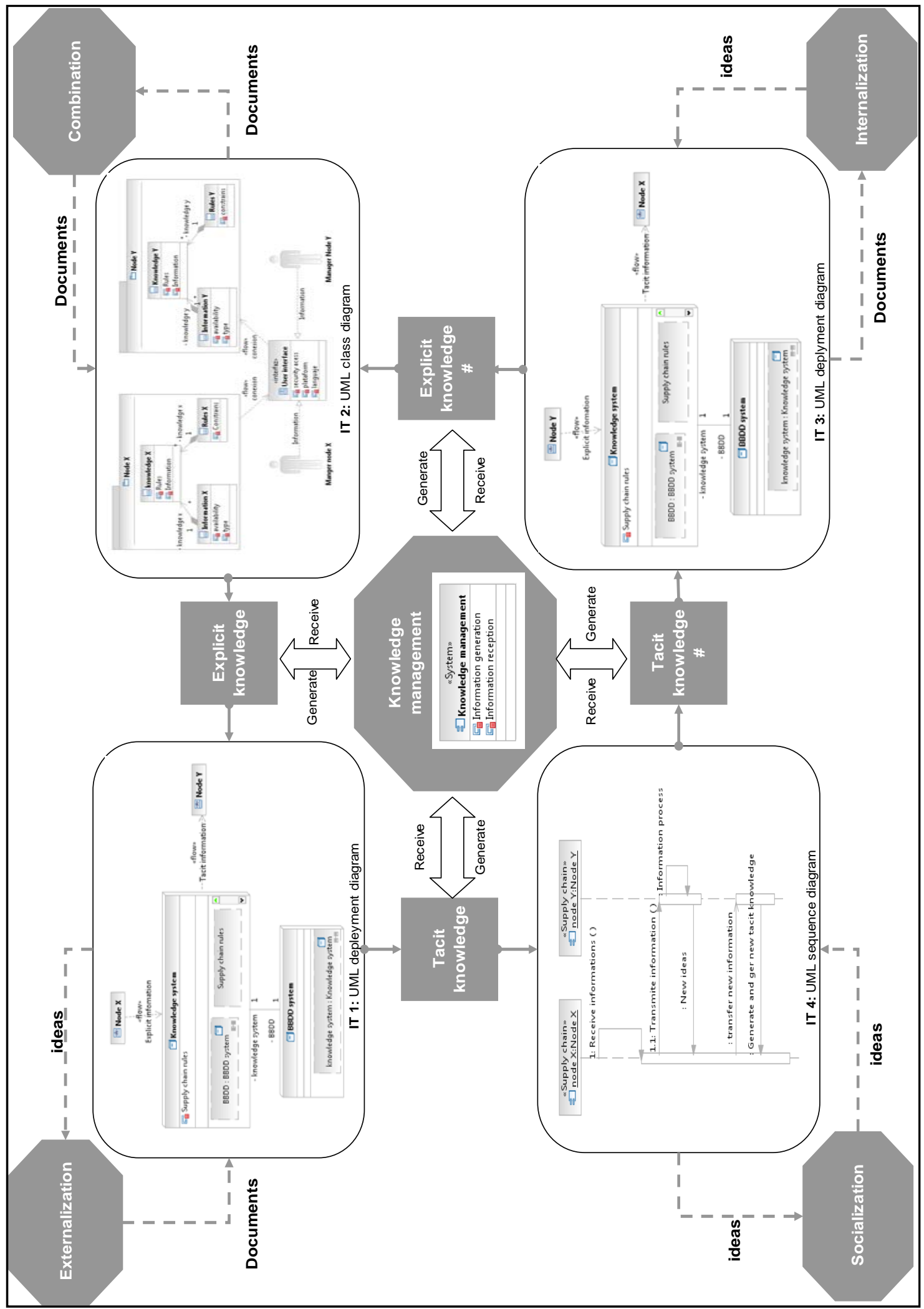

Figure 3. "Collaborative knowledge management UML-based framework. A conceptual perspective". 
knowledge process considers the rules and information from the information exchange process by considering a composition association to express which component classes are used to support the main knowledge class process. Next, the information class not only considers the availability and type of information as main attributes, but also the rules which apply either in the system or the SC nodes.

- IT 3, the deployment diagram: here the $Y$ and $X$ nodes are represented by an artefact where the information flow enters and exits the knowledge system node to represent tacit and explicit knowledge, respectively. In addition, a knowledge system is connected to another node which represents a database (BBDD) system by considering a one-to-one relationship given the fact that there must be a correct correspondence with shared information (tacit and explicit).

- IT 4, the sequence diagram: this diagram has been used to represent the actions related to transforming tacit knowledge into new tacit knowledge. Therefore, this diagram represents how node $X$ receives information (tacit knowledge), transforms it, and then transmits it to node $Y$ for it to be reprocessed to obtain new tacit information. As the product is intangible, the sequence diagram provides an accurate view to not only capture and transmit the activities related to such intangible products, but to also understand how the process is carried out.

Finally, each IT is presented from a conceptual perspective (Figure 3) by extending the centralised model in Figure 1. Therefore, this conceptual framework represents the overall view of the proposal.

\subsection{A conceptual example of a collaborative UML-based sequence diagram for the supply chain: Socialisation}

As seen in Figure 3, four processes are considered (socialisation, externalisation, combination and internationalisation) in the proposed collaborative knowledge management framework (CKMF), and each of these processes is supported by the corresponding IT, which are related to the appropriate UML-based model. Yet each UML-based model will depend on the real supply chain configuration where the CKMF will be applied. Hence, this subsection shows one of those UML-based models 
when a particular SC is considered which belongs to a specific environment/sector supply chain. Then, as Figure 4 shows, this specific SC comprises three nodes (supplier, manufacturer and customer 3 ). Moreover, the selected process to be represented (as an example) is the socialisation process which considers a sequence UML-based diagram in relation to its simplest understanding and representation.

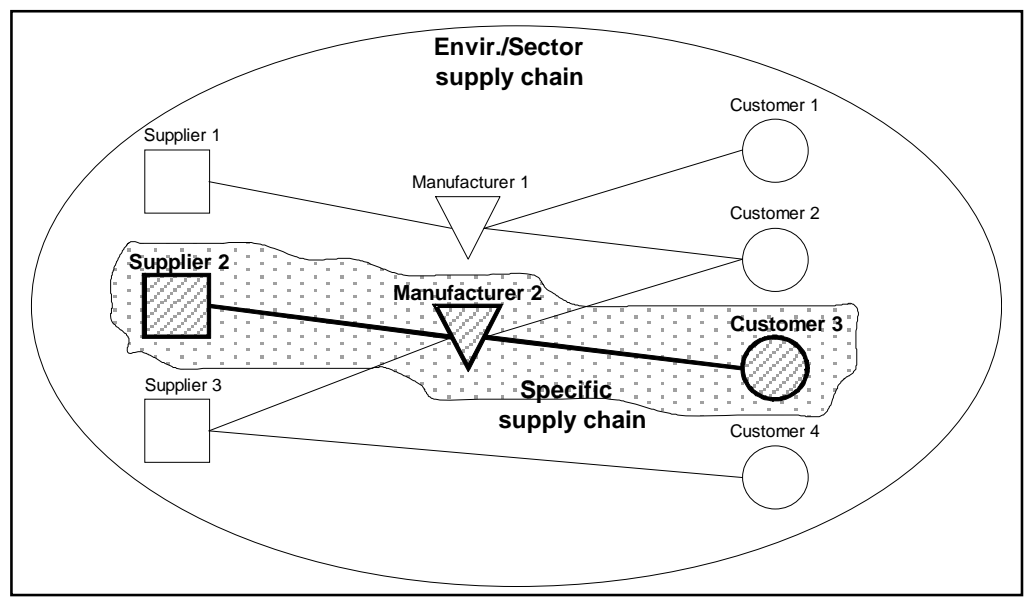

Figure 4. "Supply chain conceptualisation".

Thus, the behaviour of the nodes will establish the main characteristics to be considered and the protocols which will work to allow the communication and message exchange process among nodes which will support the collaborative processes. In this context, the proposed example considers the case of a collaborative inventory management process (Figure 5) where a customer, manufacturer and supplier are identified. Initially, the messages among them flow from customer to manufacturer. The manufacturer should establish if it is capable of accomplishing the costumer's request according to his/her current situation or if he/she should negotiate modifications in the delivery time and quantities. In relation to the collaboration between these supply chain nodes, planning will then consider the answer that the customer could send to the manufacturer. Therefore messages flow effectively, plans are generated and requirements are provided with the most effective answers. This also facilitates the agreement processing order to support the corresponding collaborative process among the nodes of the SC. 


\subsection{Limitations}

The proposed framework is not without its limits. Firstly, it has been developed theoretically to cover the concepts of the collaborative supply chain management under a knowledge management point of view. In light of this, this framework must be submitted to test the real system in order to compare the results obtained with the model with the real system behaviour. Secondly, KM itself encompasses many research subjects, topics and areas, and the framework presented in this paper only focuses on the information sharing process.

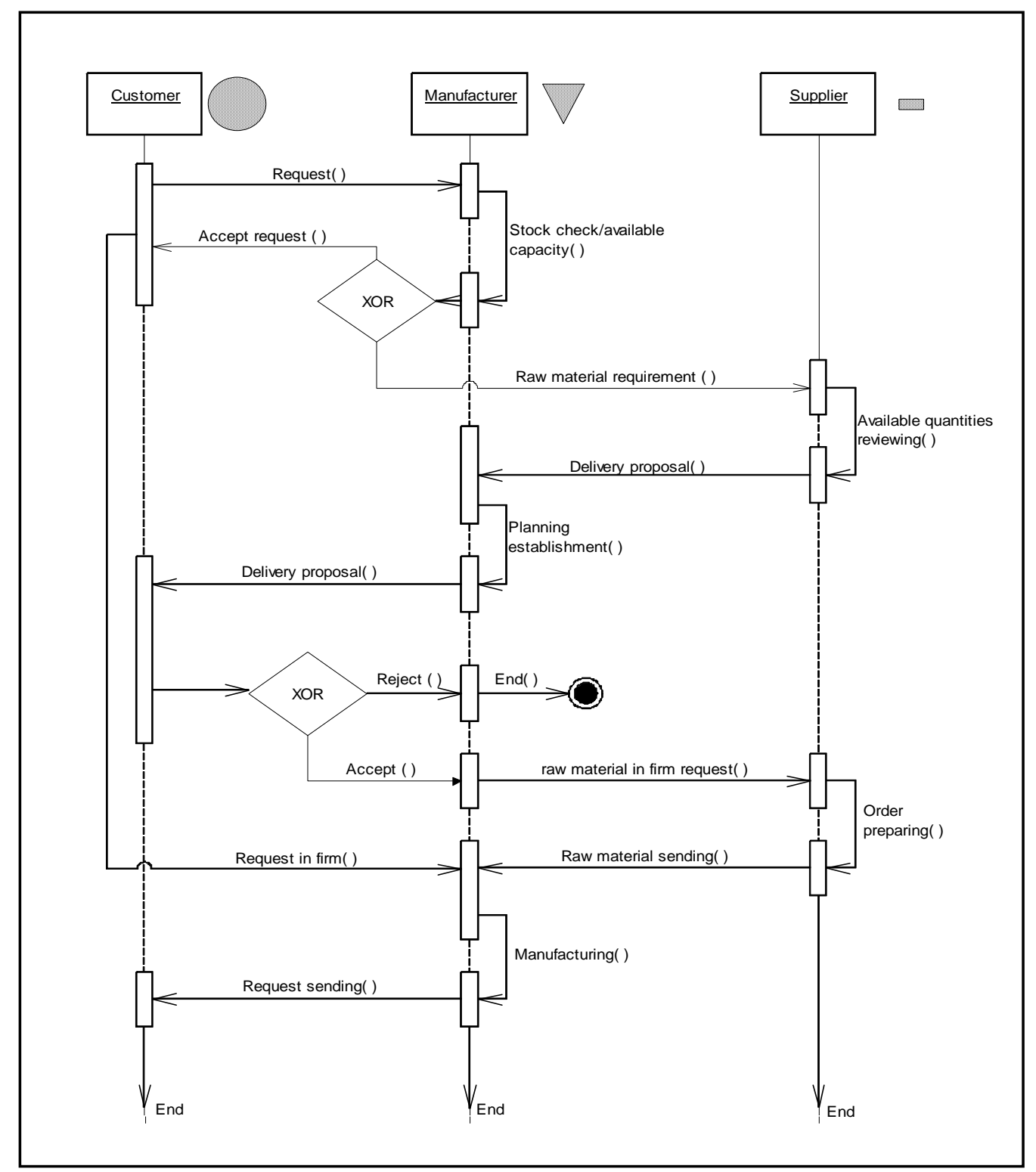

Figure 5. "UML sequence model for the supply chain". 


\section{Conclusions}

In the most general cases, collaborative activities imply a distributed decisionmaking process which involves several SC nodes. In this paper, a collaborative UML-based KMF architecture is proposed. In addition, this proposal summarises existing knowledge, and it not only fulfils, but enriches each of its components with the modeller's own knowledge. Another important aspect is that the final model representation will depend on the specific environment or SC being considered. Thus, a specific SC (made up of a supplier, a manufacturer and a customer) has been considered in this paper. In this context, and in order to support and represent the collaborative management process (mainly addressed to support the information exchange), the interaction among them is represented by a sequence UML-based model. For future research, the model will be extended to solve interoperability matters in a real environment by considering technologies and standards in an open-source context to implement the proposed collaborative framework, and by also considering languages other than UML for each IT presented in the CKMF.

\section{Acknowledgements}

This research has been carried out in the framework of a project funded by the Spanish Ministry of Science and Education entitled 'Simulation and evolutionary computation and fuzzy optimisation models of transportation and production planning processes in a supply chain. Proposal of collaborative planning supported by multi-agent systems. Integration in a decision system. Applications" (EVOLUTION project, DPI2007-65501).

\section{References}

Aurum, A., Daneshgara, F. \& Warda, J. (2008). Investigating Knowledge Management practices in software development organisations - An Australian experience. Information and Software Technology, 50(6), 511-533.

Bafoutsou, G., \& Mentzas, G. (2002). Review and functional classification of collaborative systems. International Journal of Information Management, 22(4), 281-305. 
Barratt, M. (2004). Understanding the meaning of collaboration in the supply chain. Supply Chain Management: An International Journal, 9(1), 30-42.

Beamon, B. M., \& Chen, V. C. P. (2001). Performance analysis of conjoined supply chains. International J ournal of Production Research, 39(14), 3195-3218.

Blanc, S., Ducq, Y., \& Vallespir, B. (2007). Evolution management towards interoperable supply chains using performance measurement. Computers in Industry, 58(7), 720-732.

Booch, G., Rumbaugh, J., \& Jacobson, I. (1997). The Unified Modeling Language user guide. Addison-Wesley.

Boddy, D., Macbeth, D., \& Wagner, B. (2000). Implementing Collaboration Between Organizations: An Empirical Study Of Supply Chain Partnering. Journal of Management Studies, 37(7), 1003-1018.

Chen, M. C., Yang, T., \& Li, H. C. (2007). Evaluating the supply chain performance of IT-based inter-enterprise collaboration. Information \& Management, 44(6), 524-534.

Cooper, M., Eilram, L. M., Gardner J. T., \& Hanks, A. M. (1997). Meshing Multiple alliances. Journal of Business Logistics, 18(I), 67-89. Retrieved November $24^{\text {th }}$, 2008,from http://findarticles.com/p/articles/mi_qa3705/is_199701/ai_n8753721.

Dubey, V., Veeramani, R., \& Gutierrez, A. (2002, January). B2B Supply Chain Management Workgroup Report of Findings on "Internet-Based Models for Interaction With Suppliers of Direct Materials". B2B SCM Workgroup Report, 0-28.

Dyer, J. H., \& Singh, H. (1998). The relational view: cooperative strategy and sources of interorganizational competitive advantage. Academy of Management Review, 23(4), 660-679.

Eng, T. Y. (2004). The role of e-marketplaces in supply chain management. Industrial Marketing Management, 33(2), 97-105.

Fawcett, S. E., Osterhaus, P., Magnan, G. M., Brau, J. C. \& McCarter, M. W. (2007). Information sharing and supply chain performance: the role of connectivity and willingness. Supply Chain Management: An International Journal, 12(5), 358-368. 
Fawcett, S. E., Magnan, G. M. \& McCarter, M. W. (2008). Benefits, barriers, and bridges to effective supply chain management. Supply Chain Management: An International J ournal, 13(1), 35-48.

Giannoccaro, I., \& Pontrandolfo, P. (2001, March). Models for supply chains management: a taxonomy. Paper presented at the Production and Operations Management Conference (POMS) "Mastery in the New Millennium", Orlando, FL.

Grangel, R., Chalmeta, R., \& Campos, C. (2007a). A Modelling Framework for Sharing Knowledge. Lecture Notes in Computer Science (Ed.), Knowledge-Based Intelligent Information and Engineering Systems (pp. 1230-1237). Berlin: Springer.

Grangel, R., Chalmeta, R., \& Campos, C. (2007b, October). Using UML Profiles for Enterprise Knowledge Modelling. Paper presented at the EDOC Conference Workshop, Eleventh International IEEE (pp. 125-132), Annapolis, Maryland.

Grangel, R., Chalmeta, R., Campos, C., Sommar, R., \& Bourey, J. (2008). A Proposal for Goal Modelling Using a UML Profile. Enterprise Interoperability III (pp. 679-690). London: Springer.

Gunasekaran, A., \& Ngai, E. W. T. (2005). Build-to-order supply chain management: a literature review and framework for development. Journal of Operations Management, 23(5), 423-451.

Gunasekaran, A., Lai, K., \& Cheng, T. C. E. (2008). Responsive supply chain: A competitive strategy in a networked economy. Omega: International Journal of Management Science, 36(4), 549-564.

Hernández, J. E., Mula, J., Ferriols, F. J., \& Poler, R. (2008). A conceptual model for the production and transport planning process: An application to the automobile sector. Computers in Industry, 59(8), 842-852.

Hall, R., \& Adriani, P. (1998). Management Focus Analysing Intangible Resources and Managing Knowledge in a Supply Chain Context. European Management Journal, 16(6), 685-697. 
Han, S. H., Chin, K. H., \& Chae, M. J. (2007). Evaluation of CITIS as a collaborative virtual organization for construction project management. Automation in Construction, 16(2), 199-211.

Holweg, M., Disney, S., Holmstrom, J., \& Smaros, J. (2005). Supply Chain Collaboration: Making Sense of the Strategy Continuum. European Management Journal, 23(2), 170-181.

Hoyt, J., \& Huq, F. (2000). From arms-length to collaborative relationships in the supply chain. International Journal of Physical Distribution \& Logistics Management, 30(9), 750-764.

Huang, S., Chu, Y., Li, S., \& Yen, D. C. (2008). Enhancing conflict detecting mechanism for Web Services composition: A business process flow model transformation approach. Information and Software Technology, 50(11), 10691087.

Ketikidis, P. H., Koh, S. C. L., Dimitriadis, N., Gunasekaran, A. \& Kehajova, M. (2008). The use of information systems for logistics and supply chain management in South East Europe: Current status and future. Omega: International J ournal of Management Science, 36(4), 592-599.

Kwon, O., Im, G. P., \& Lee, K. C. (2007). MACE-SCM: A multi-agent and casebased reasoning collaboration mechanism for supply chain management under supply and demand uncertainties. Expert Systems With Applications, 33(3), 690705.

La Forme, F. G., Genoulaz, V. B., \& Campagne, J. A. (2007). Framework to analyse collaborative performance. Computers in Industry, 58(7), 687-697.

Lambert, M. D., \& Cooper, M. C. (2000). Issues in supply chain management. Industrial Marketing Management, 29(1), 65-83.

Lejeune, M. A., \& Yakova, N. (2005). On characterizing the 4 C's in supply chain management. J ournal of Operations Management, 23(1), 81-100.

Manthou, V., Vlachopoulou, M., \& Folinas, D. (2004). Virtual e-Chain (VeC) model for supply chain collaboration. International Journal of Production Economics, $87(3), 241-250$. 
Meixell, M. J., \& Gargeya, V. B. (2005). Global supply chain design: A literature review and critique. Transportation Research Part E, 41(6), 531-550.

Lin, H. K., \& Harding, J. A. (2007). A manufacturing system engineering ontology model on the semantic web for inter-enterprise collaboration. Computers in Industry, 58(5), 428-437.

Ni, Q., Lu, W. F., Yarlagadda, P. K. D. V., \& Ming, X. (2006). A collaborative engine for enterprise application integration. Computers in Industry, 57(7), 640-652.

Nonaka, I. (1991, November). The Knowledge-Creating Company. Harvard Business Review, 96-104.

Núñez, P. I. A., \& Núñez, G. Y. (2005). Propuesta de clasificación de las herramientas-software para la gestión del conocimiento. ACIMED, 13(2). Retrieved December $\quad 6^{\text {th }}$, 2008, from http://bvs.sld.cu/revistas/aci/vol13_2_05/aci03_05.htm.

Rosenzweig, E. D., \& Roth, A. V. (2007). B2B seller competence: Construct development and measurement using a supply chain strategy lens. Journal of Operations Management, 25(6), 1311-1331.

Saad, M., Jones, M., \& James, P. (2002). A review of the progress towards the adoption of supply chain management (SCM) relationships in construction. European Journal of Purchasing and Supply Management, 8(3), 173-183.

Sahay, B. S. (2003). Understanding trust in supply chain relationships. Industrial Management \& Data Systems, 103(8), 553-563.

Sigala, M. (2008). A supply chain management approach for investigating the role of tour operators on sustainable tourism: the case of TUI. Journal of Cleaner Production, 16(15), 1589-1599.

Simatupang, T. M. \& Sridharan, R. (2002). The Collaborative Supply Chain. The International J ournal of Logistics Management, 13(1), 15-30.

Skjoett-Larsen, T., Thernøe, C., \& Andresen, C. (2003). Supply chain collaboration: Theoretical perspectives and empirical evidence. International Journal of Physical Distribution \& Logistics Management, 33(6), 531 - 549. 
Smirnov, A. V., \& Chandra, Ch. (2000). Ontology-Based Knowledge Management for Cooperative Supply Chain Configuration. Retrieved December $9^{\text {th }}, 2008$, from http://citeseer.ist.psu.edu/521197.html.

Son, J. Y., \& Sheu, C. (2008). The impact of replenishment policy deviations in a decentralized supply chain. International J ournal of Production Economics, 113(2), 785-804.

Soylu, A., Oruc, C., Turkay, M., Fujita, K. \& Asakura, T. (2006). Synergy analysis of collaborative supply chain management in energy systems using multi-period MILP. European J ournal of Operational Research, 174(1), 387-403.

Tann, W., \& Shaw, H. (2007). The collaboration modelling framework for ship structural design. Ocean Engineering, 34(5-6), 917-929.

Trappey, A. J. C., \& Hsiao, D. W. (2008). Applying collaborative design and modularized assembly for automotive ODM supply chain integration. Computers in Industry, 59(2-3), 277-287.

Turkay, M., Oruc, C., Fujita, K. \& Asakura, T. (2004). Multi-company collaborative supply chain management with economical and environmental considerations. Computers and Chemical Engineering, 28(6-7), 985-992.

Ulieru, M., Norrie, D., Kremer, R., \& Shen, W. (2000). A multi-resolution collaborative architecture for web-centric global manufacturing. Information Sciences, 127(1-2), 3-21.

van der Vaart, T., \& van Donka, D. P. (2008). A critical review of survey-based research in supply chain integration. International Journal of Production Economics, 111(1), 42-55.

Williamson, E. A., Harrison, D. K., \& Jordan, M. (2004). Information systems development within supply chain management. International Journal of Information Management, 24(5), 375-385.

Yesilbas, L. G., \& Lombard, M. (2004). Towards a knowledge repository for collaborative design process: focus on conflict management. Computers in Industry, 55(3), 335-350. 


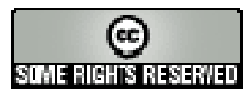

Article's contents are provided on a Attribution-Non Commercial 3.0 Creative commons license. Readers are allowed to copy, distribute and communicate article's contents, provided the author's and Journal of Industrial Engineering and Management's names are included. It must not be used for commercial purposes. To see the complete license contents, please visit http://creativecommons.org/licenses/by-nc/3.0/. 